\title{
Pattern of chromosomal changes in 'beta' Anolis (Norops group) (Squamata: Polychrotidae) depicted by an ancestral state analysis
}

\author{
Riccardo Castiglia ${ }^{1 *}$, Oscar Flores-Villela², Alexandra Maria Ramos Bezerra ${ }^{3,4}$, Antonio Muñoz ${ }^{5}$ \\ and Ekaterina Gornung ${ }^{1}$
}

\begin{abstract}
Background: Neotropical lizards, genus Anolis (Polychrotidae), with nearly 380 species, are members of one of the most diversified genera among amniotes. Herein, we present an overview of chromosomal evolution in 'beta' Anolis (Norops group) as a baseline for future studies of the karyotypic evolution of anoles. We evaluated all available information concerning karyotypes of Norops, including original data on a recently described species, Anolis unilobatus. We used the phylogeny of Norops based on DNA sequence data to infer the main pattern of chromosomal evolution by means of an ancestral state analysis (ASR).

Results: We identified 11 different karyotypes, of which 9 in the species had so far been used in molecular studies. The ASR indicated that a change in the number of microchromosomes was the first evolutionary step, followed by an increase in chromosome numbers, likely due to centric fissions of macrochromosomes. The ASR also showed that in nine species, heteromorphic sex chromosomes most probably originated from six independent events.

Conclusions: We observed an overall good correspondence of some characteristics of karyotypes and species relationships. Moreover, the clade seems prone to sex chromosome diversification, and the origins of five of these heteromorphic sex chromosome variants seem to be recent as they appear at the tip nodes in the ancestral character reconstruction. Karyotypic diversification in Norops provides an opportunity to test the chromosomal speciation models and is expected to be useful in studying relationships among anole species and in identifying cryptic taxa.
\end{abstract}

Keywords: Anole; Anolis; Chromosomal evolution; Cytogenetics; Norops; Sex chromosomes; Systematics

\section{Background}

The genus Anolis includes nearly 380 species of neotropical lizards and is the most species-rich amniote genus (Uetz 2013). Anolis was recently the subject of a systematic revision that resulted in it being split into eight different genera (Nicholson et al. 2012). However, this systematic arrangement has been vigorously criticized (e.g., Poe 2013), and in this paper, we adopted the classical view that considers anole lizards as being comprised of a single genus (Losos 2009; Uetz 2013). Anole species are distributed throughout the Caribbean islands

\footnotetext{
*Correspondence: castiglia@uniroma1.it

'Dipartimento di Biologia e Biotecnologie 'Charles Darwin', Università di Roma 'La Sapienza', via A. Borelli 50, Rome 00161, Italy

Full list of author information is available at the end of the article
}

and mainland Americas from Texas to tropical South America (reviewed in Losos 2009), where they exhibit a wide array of ecological and morphological specializations (Etheridge 1959; Williams 1983; Losos et al. 1998; Köhler 2000). Anoles have been thoroughly investigated in various ecological, behavioral, and evolutionary studies (reviewed in Losos 2009). One species, the green anole lizard Anolis carolinensis, was the first reptile genome to be sequenced. This achievement may considerably advance research outcomes on various biological aspects of anoles (Alföldi et al. 2011).

Based on a single osteological character, i.e., the presence/absence of caudal transverse processes, Etheridge (1959) divided Anolis into major sections: 'alpha' anoles, which lack this morphological trait, and 'beta' anoles 
(Norops), which carry the trait. In a recent revision and in a previous report, based on molecular phylogenetics (Poe 2004; Nicholson et al. 2012), Norops was recognized as a monophyletic group that includes 169 species.

Karyological studies in anoles were very intensive in the 1970s and 1980s, especially studies that were conducted by Gorman and coworkers who defined karyotypes of numerous species (Gorman 1973). Since then, scientific interest has shifted to other fields of study, and the chromosomal evolution of anoles has not been further investigated. Indeed, only a few papers in this regard were published from 1980 to the present (Blake 1986; Brandley et al. 2006; Castiglia et al. 2010). However, anoles exhibit remarkable inter- and intraspecific variations in chromosome number and morphology as well as in the presence/absence of heteromorphic sex chromosomes. For this reason, investigating speciation of anoles as driven by chromosomal changes remains challenging. Moreover, chromosomal variability is expected to be useful in studying relationships among anole species and in identifying cryptic taxa.

Herein, we present an overview of the chromosomal evolution in Norops as a baseline for future studies of the karyotypic evolution of anoles. Previous phylogenetic reconstructions of anoles, which also included chromosomal data, applied them in the same matrix together with molecular and morphological characters (Poe 2004; Brandley et al. 2006). In contrast, our approach consists of inferring the pattern of chromosomal evolution in a phylogeny purely based on molecular data. A similar approach was recently used for an ancestral state reconstruction (ASR) of chromosomal characters in some other reptilian clades, such as the Phrynosomatidae (genus Sceloporus) (Leaché and Sites 2009), Gekkonidae (Gamble 2010), and Serpentes (Oguiura et al. 2009). For this study, we reviewed all available data on karyotypes of Norops and also included original data on one recently described species, A. unilobatus (Köhler and Vesely 2010). We used the phylogeny of Norops based on DNA sequence data to infer the main pattern of chromosomal evolution by means of an ASR. ASR analysis allowed us to test whether karyotypic diversity matched phylogenetic relationships among species and enabled us to track the direction of chromosomal change. We also tested a hypothesis of an ancient common origin of heteromorphic sex chromosomes vs. their independent origin in different species.

\section{Methods}

\section{Materials}

We examined published karyotypes of Norops species for the shape of macrochromosomes, the number of microchromosomes, the presence/absence of sex chromosomes, and their size and shape (Table 1). One additional species,
A. unilobatus, was newly studied and included in this survey. One male and three female A. unilobatus were collected in dry tropical forest located in the Reserva da Biosfera Sepultura, Chiapas State, Mexico. Field numbers cited in the text (RCMX) belong to Riccardo Castiglia. Animals were managed following all applicable institutional animal care guidelines, and all required state and federal permits were obtained.

Femurs were taken from individuals after an intraperitoneal injection of vinblastine sulfate, Velbe (Lilly, Italy) $(1: 1,000)$ for $1 \mathrm{~h}$. Samples were then processed following procedures described in Castiglia et al. (2010). Pictures of metaphases were collected using a Photometrics Sensys 1600 digital camera (Roper Scientific Photometrics, Tucson, AZ, USA).

DNA was extracted from tissues preserved in 100\% ethanol using the QIAmp tissue extraction kit (Qiagen, Hilden, Germany). The mitochondrial ND2 gene, five transfer ( $t$ ) RNAs, the origin of light-strand replication, and a portion of the cytochrome oxidase subunit 1 (CO1) gene were amplified with primers designed by Macey et al. (1999) as follows: L4160 ND1 5'CGATTCCGATATGACCARCT-3', H4980 ND2 5'ATTTTTCGTAGTTGGGTTTGRTT-3', L4437 tRNAMet 5' -AAGCTTTCGGGCCCATACC-3', and H5934a CO1 5'-AGRGTGCCAATGTCTTTGTGRTT-3'.

We used a Bayesian algorithm to construct a phylogeny based on mitochondrial DNA sequences (NDH2, 5 tRNAs, the origin of light-strand replication, and a portion of the CO1 gene) that included all 62 species for which mtDNA sequences were available in GenBank (mainly published by Nicholson et al. 2005), plus A. unilobatus. The final alignment consisted of 1,406 bp.

Data were partitioned by the codon position with a separate partition for each gene. The general time reversible substitution model with gamma-distributed rate heterogeneity and the proportion of invariant sites were used for each partition. For the Bayesian analysis, two independent Monte Carlo (MCMC) analyses were run with MrBayes 3.2 (Ronquist et al. 2012). We used $3 \times$ $10^{6}$ generations, four chains, and a burn-in of $10 \%$ of the generated tree. Anolis cristatellus (AF528724) and A. distichus (AF528725) were used as outgroups (Nicholson et al. 2005).

The consensus tree was pruned so as to eliminate species for which chromosomal data were unknown. The resulting tree, including 31 Norops species, was used for the ASR analysis that was performed with Mesquite 2.74 software (Maddison and Maddison 2011). A maximum likelihood (ML) reconstruction method was used to reconstruct the ancestral states. We used the one-rate MK1 model (Lewis 2001), the only model in Mesquite allowing multistate characters, and proportional likelihood (PL) values were used to determine which state was the most likely. Preliminarily, 
Table 1 Karyological data of Norops species

\begin{tabular}{|c|c|c|c|c|c|}
\hline Species & Karyotype & Macrochromosomes & Microchromosomes & Sex chromosomes & Source \\
\hline Anolis mestrei & 28 & $14 \mathrm{M} / \mathrm{SM}$ & 14 & - & Gorman and Atkins (1968) \\
\hline Anolis homolechis & 28 & $14 \mathrm{M} / \mathrm{SM}$ & 14 & - & Gorman and Atkins (1968) \\
\hline Anolis quadriocellifer & 28 & $14 \mathrm{M} / \mathrm{SM}$ & 14 & - & Gorman and Atkins (1968) \\
\hline Anolis rubribarbus & 28 & $14 \mathrm{M} / \mathrm{SM}$ & 14 & - & Gorman and Atkins (1968) \\
\hline Anolis sagrei & $\begin{array}{l}\text { 29-30 } \\
\text { (type-B) }\end{array}$ & $18 \mathrm{M} / \mathrm{SM}$ & Male 11 Female $12^{\mathrm{a}}$ & $X_{1} X_{2} Y-X_{1} X_{1} X_{2} X_{2}^{a}$ & De Smet (1981) \\
\hline Anolis lineatopus & 30 (type-A) & $14 \mathrm{M} / \mathrm{SM}$ & 16 & - & Gorman $(1965,1969)$ \\
\hline Anolis valencienni & 30 (type-A) & $14 \mathrm{M} / \mathrm{SM}$ & 16 & - & Gorman and Atkins (1968) \\
\hline Anolis garmani & 30 (type-A) & $14 \mathrm{M} / \mathrm{SM}$ & 16 & - & Gorman and Atkins (1968) \\
\hline Anolis lineatus & 30 (type-A) & $14 \mathrm{M} / \mathrm{SM}$ & 16 & - & Gorman and Atkins (1968) \\
\hline $\begin{array}{l}\text { Anolis nitens = Anolis } \\
\text { chrysolepis }\end{array}$ & 30 (type-A) & $14 \mathrm{M} / \mathrm{SM}$ & 16 & - & Gorman (1973) \\
\hline Anolis auratus & 30 (type-A) & $14 \mathrm{M} / \mathrm{SM}$ & 16 & - & $\begin{array}{l}\text { Gorman et al. (1967), } \\
\text { De Smet (1981) }\end{array}$ \\
\hline Anolis aquaticus & 30 (type-A) & $14 \mathrm{M} / \mathrm{SM}$ & 16 & - & $\begin{array}{l}\text { Gorman unpublished } \\
\text { (in Lieb 1981) }\end{array}$ \\
\hline Anolis conspersus & 30 (type-B) & $14 \mathrm{M} / \mathrm{SM}$ & 16 & $\begin{array}{l}\text { XY (seventh) (similar } \\
\text { sizes) }\end{array}$ & Gorman and Atkins (1966) \\
\hline Anolis opalinus & 30 (type-B) & $14 \mathrm{M} / \mathrm{SM}$ & 16 & $\begin{array}{l}\text { XY (seventh) (similar } \\
\text { sizes) }\end{array}$ & Gorman (1969) \\
\hline Anolis onca & 30 (type-B) & $14 \mathrm{M} / \mathrm{SM}$ & 16 & $\begin{array}{l}\text { XY (seventh) (similar } \\
\text { sizes) }\end{array}$ & Gorman (1969) \\
\hline Anolis grahami & $30 \sim 37$ & 14 M/SM-10 M/SM, 9A, ST & $16-18^{b}$ & - & De Smet (1981) \\
\hline Anolis biporcatus & $\begin{array}{l}\text { 29-30 } \\
\text { (type-A) }\end{array}$ & $\begin{array}{l}\text { Male: } 13 \mathrm{M} / \mathrm{SM}, 1 \mathrm{~A} \text {; female: } \\
12 \mathrm{M} / \mathrm{SM}, 2 \mathrm{~A}\end{array}$ & Male 15 , female 16 & $X_{1} X_{2} Y-X_{1} X_{1} X_{2} X_{2}$ & Gorman and Atkins (1966) \\
\hline Anolis nebulosus & 30 (type-C) & $14 \mathrm{M} / \mathrm{SM}$ & 16 & XY (different sizes) & $\begin{array}{l}\text { Lieb (1981), Castiglia et al. } \\
\text { (2010) }\end{array}$ \\
\hline Anolis quercorum & 30 (type-C) & $14 \mathrm{M} / \mathrm{SM}$ & 16 & XY (different sizes) & Lieb (1981) \\
\hline Anolis gracilipes & 36 & $8 \mathrm{M} / \mathrm{SM} ; 12 \mathrm{~A}$ & 16 & - & Gorman (1973) \\
\hline Anolis liogaster & 38 & $6 \mathrm{M} / \mathrm{SM} ; 16 \mathrm{~A}$ & 16 & XY (different sizes) & Lieb (1981) \\
\hline Anolis omiltemanus & 38 & $6 \mathrm{M} / \mathrm{SM} ; 16 \mathrm{~A}$ & 16 & XY (different sizes) & Lieb (1981) \\
\hline Anolis gadovii & 36 & $8 \mathrm{M} / \mathrm{SM} ; 12 \mathrm{~A}$ & 16 & XY (different sizes) & Lieb (1981) \\
\hline Anolis unilobatus & 40 & $20 \mathrm{SM} / \mathrm{ST}, 4 \mathrm{M}$ & 16 & XY (different sizes) & Present data \\
\hline Anolis tropidolepis & 40 & $24^{c}$ & 16 & - & Gorman (1973) \\
\hline Anolis fuscoauratus & 40 & $24^{c}$ & 16 & - & Gorman (1973) \\
\hline Anolis humilis & 40 & $24^{c}$ & 16 & - & Gorman (1973) \\
\hline Anolis cupreus & 40 & $4 \mathrm{M} / \mathrm{SM} ; 20 \mathrm{~A}$ & 16 & - & Gorman (1973) \\
\hline Anolis polylepis & 40 & $24^{c}$ & 16 & - & Gorman (1973) \\
\hline Anolis tropidonotus & 40 & $24^{c}$ & 16 & - & Gorman (1973) \\
\hline Anolis capito & 40 & $24^{c}$ & 16 & - & Gorman (1973) \\
\hline Anolis limifrons & 40 & $24^{c}$ & 16 & - & Gorman (1973) \\
\hline Anolis lionotus & 40 & $24^{c}$ & 16 & - & Gorman (1973) \\
\hline Anolis tropidogaster & 40 & $4 \mathrm{M} / \mathrm{SM} ; 20 \mathrm{~A}$ & 16 & - & Gorman (1973) \\
\hline Anolis intermedius & 40 & $24^{c}$ & 16 & - & $\begin{array}{l}\text { Gorman unpublished } \\
\text { (in Lieb 1981) }\end{array}$ \\
\hline
\end{tabular}


Table 1 Karyological data of Norops species (Continued)

\begin{tabular}{|c|c|c|c|c|c|}
\hline Anolis dunni & 40 & $4 \mathrm{M} / \mathrm{SM} ; 20 \mathrm{~A}$ & 16 & XY (different sizes) & Lieb (1981) \\
\hline Anolis taylori & 40 & $4 \mathrm{M} / \mathrm{SM} ; 20 \mathrm{~A}$ & 16 & XY (different sizes) & Lieb (1981) \\
\hline Anolis nebuloides & 42 & ND & ND & XY (different sizes) & Lieb (1981) \\
\hline
\end{tabular}

$\mathrm{M}$, metacentric; SM, submetacentric; A, acrocentric; ST, subtelocentric; ND, no distinction was made between macro- and microchromosomes. ${ }^{a}$ Inferred from the male karyotype; ${ }^{b}$ the presence of inter-individual variation of microchromosomes; ${ }^{c}$ the morphology of macrochromosomes was not studied.

we also performed an ASR by maximum parsimony (MP) (not shown) and altered the assumption of an equal cost for state changes building different step matrices in Mesquite. The results obtained with the ML and MP methods were highly congruent. Thus, we decided to show only the results obtained with ML because one problem with the parsimony ASR is the fact that supports at nodes are usually represented as unambiguous, often obscuring the actual degree of support for alternative character states (Cunningham 1999).

We coded different karyotypic characteristics as categorical characters (as for Serpentes in Oguiura et al. 2009). In fact, both the chromosomal number (2n) and the number of chromosomal arms (FN) may discretely change by several simultaneous chromosomal rearrangements. The presence/absence of sex chromosomes can be used as a straightforward categorical character.

The choice of an outgroup is a crucial step in the ASR. According to Nicholson et al. (2005), the sister group of Norops is the clade of anoles composed of species that belong to the 'bimaculatus', 'cristatellus', and 'distichus' groups. Unfortunately, there is uncertainty about the identity of the basal karyotype in this highly diversified clade (Olmo and Signorino 2005; Brandley et al. 2006). All of these species are characterized by a heteromorphic $\mathrm{XY}$ or an $\mathrm{X}_{1} \mathrm{X}_{1} \mathrm{X}_{2} \mathrm{X}_{2} / \mathrm{X}_{1} \mathrm{X}_{2} \mathrm{Y}$ sex chromosome system. Therefore, the outgroup was considered uncertain with the exception of the constitution of sex chromosomes. We first performed an ASR by considering the karyotype as a single character with nine different states corresponding to different karyotypes.

We then separately considered some karyotype characteristics. First, we coded the different karyotypes in Norops as a two-state character: state 0 , karyotypes with 7 9 pairs of macrochromosomes $(28<2 n<30)$, and state 1 , karyotypes with 12 pairs of macrochromosomes $(2 \mathrm{n}=$ $40)$. The karyotype of $A$. nebuloides $(2 \mathrm{n}=42)$ was coded as state 1 , even though it does not show a distinction between macro- and microchromosomes, because the diploid number is similar to that observed in species with a high number of macrochromosomes. The polymorphic karyotype in A. grahami $(30<2 \mathrm{n}<37)$ was coded as state 1 since polymorphic states are not allowed under the likelihood ASR in Mesquite. However, in the preliminary analysis with the parsimony ASR, A. grahami was coded as polymorphic.
The number of microchromosomes was then coded as a five-state character: state 0,14 microchromosomes; state 1, 12 microchromosomes (female condition in A. sagrei); state 2, 16 microchromosomes; state 3,18 microchromosomes; and state 4 , the absence of microchromosomes (only observed in A. nebuloides). For micro- and macrochromosomes, the outgroup was coded as uncertain due to the observed variability in the number of chromosomes in the outgroup species (Olmo and Signorino 2005; Brandley et al. 2006).

Finally, we analyzed the emergence of heteromorphic sex chromosomes. We identified three different patterns of sex chromosomes in Norops (Table 1) and coded them in four states: state 0, the absence of heteromorphic sex chromosomes; state 1, heteromorphism at macrochromosome pair 7 (same size); state 2, multiple sex chromosomes $\mathrm{X}_{1} \mathrm{X}_{1} \mathrm{X}_{2} \mathrm{X}_{2} / \mathrm{X}_{1} \mathrm{X}_{2} \mathrm{Y}$; and state 3 , heteromorphism at one macrochromosome pair (different sizes). Character states 2 and 3 included species with slightly different heteromorphic sex chromosomes. Additional separation using more states was not feasible. We also coded 11 species as uncertain in view of the fact that the macrochromosomes in those species have not been studied in sufficient detail. The outgroup was coded as state 2 because of the presence of multiple sex chromosomes in the outgroup species.

\section{Results and discussion \\ Results \\ The karyotype of $A$. unilobatus}

Karyotypes were made from metaphase chromosomes of three females (RCMX70, RCMX71, and RCMX91) and one male (RCMX90) of A. unilobatus. All samples showed $2 \mathrm{n}=40$ with 24 macrochromosomes and 6 microchromosomes, so they are designated because they markedly differed in size (Figure 1).

The macrochromosomes of $A$. unilobatus included two pairs of metacentric, three pairs of submetacentric, and seven pairs of subtelocentric/acrocentric chromosomes (Figure 1). The shape of the microchromosomes was not easily discernible, but some biarmed elements were observed in more elongated metaphases. In the male, the smallest metacentric chromosomes (pair 11) were heteromorphic in size and likely corresponded to sex chromosomes of the XY type. 


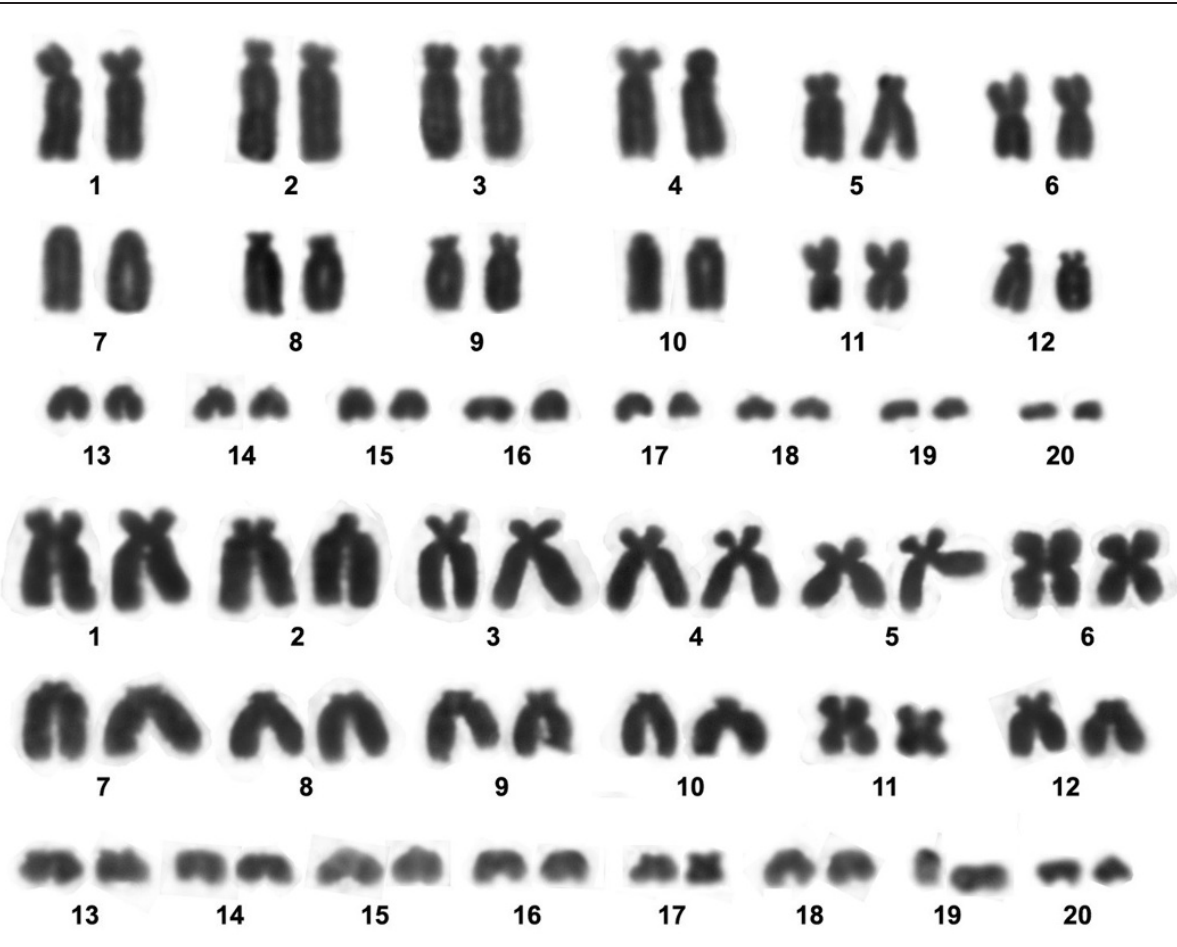

Figure 1 Karyotype of Anolis unilobatus $(\mathbf{2} \mathbf{n}=\mathbf{4 0}$ ). Female (above) and male (below). Note the heteromorphic pair 11 in the male karyotype.

\section{A literature survey of Norops karyotypes}

We found 11 different karyotypes, of which 9 were from species previously used in molecular studies. They are briefly described below. Ideograms are shown for the eight karyotypes for which the morphology of the macrochromosomes was studied in detail and molecular data were available (Figure 2). The karyological information for each species is summarized in Table 1:

- $2 n=28$. This karyotype is composed of seven pairs of biarmed macrochromosomes and seven pairs of microchromosomes. The morphology of the macrochromosomes seemed to be conserved throughout the group, even if we could not exclude small differences in the arm ratio. The chromosomes were all meta-submetacentric and unevenly decreasing in size. The shape of the microchromosomes was not classifiable in major published karyotypes. However, in A. rubribarbus and A. mestrei, one or two pairs of microchromosomes were distinctly metacentric (Gorman and Atkins 1968). The $2 \mathrm{n}=28$ karyotype was found in four species: A. mestrei, A. homolechis, A. quadriocellifer, and A. rubribarbus (Table 1).

- $2 n=30($ type- $A)$. This karyotype is composed of seven pairs of biarmed macrochromosomes and eight pairs of microchromosomes. Examining published karyotypes (Gorman and Atkins 1968;
Gorman 1969), we can say that the macrochromosomes were identical to those observed in the $2 \mathrm{n}=28$ karyotype. The only difference between the $2 n=28$ and $2 n=30$ (type-A) karyotypes was the presence of one additional pair of microchromosomes. The $2 \mathrm{n}=30$ (type-A) karyotype was found in seven species (Table 1 ).

- $2 n=30$ (type-B). Three species, A. opalinus, $A$. conspersus, and $A$. onca, had a karyotype identical to the $2 \mathrm{n}=30$ (type-A), except for the smallest pair of macrochromosomes (number 7) which was in a heteromorphic condition (submetacentric and acrocentric homologues were of similar size), thus matching the XY sex chromosome system. Unfortunately, no females of these species were studied.

- $2 n=29-30$ (type-A). Anolis biporcatus had a karyotype that resembled the $2 \mathrm{n}=30$ (type-A) but showed an $\mathrm{X}_{1} \mathrm{X}_{1} \mathrm{X}_{2} \mathrm{X}_{2} / \mathrm{X}_{1} \mathrm{X}_{2} \mathrm{Y}$ multiple sex chromosome system ( $2 n=29$ in males, $2 n=30$ in females; Gorman and Atkins 1966). $X_{1}$ is an acrocentric chromosome and $\mathrm{X}_{2}$ is a microchromosome. The $\mathrm{Y}$ chromosome is metacentric and is similar in size to $\mathrm{X}_{1}$.

- $2 n=29-30($ type-B). Males in A. sagrei showed a peculiar karyotype composed of 9 pairs of macrochromosomes and 11 pairs of 


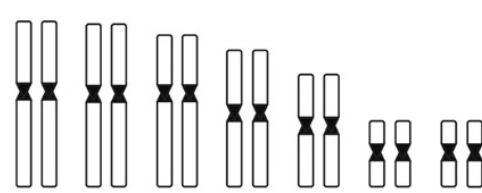

$2 n=28$

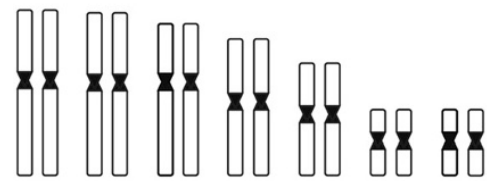

$2 n=30($ type-A)

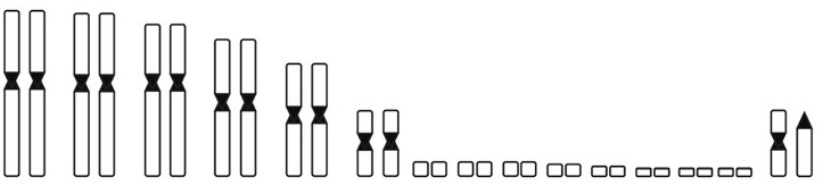

$2 n=30$ (type-B)

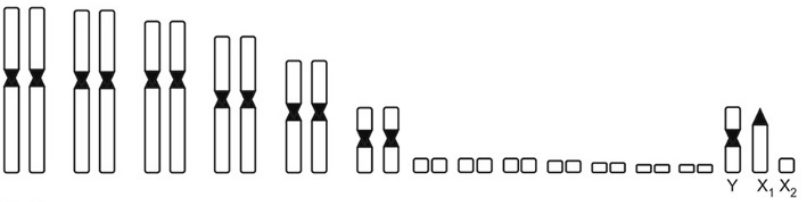

$2 n=29-30($ type-A)

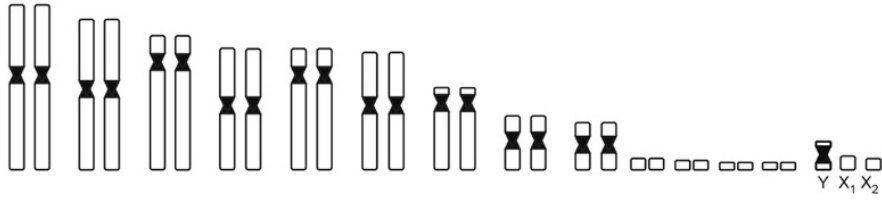

$2 n=29-30$ (type-B)

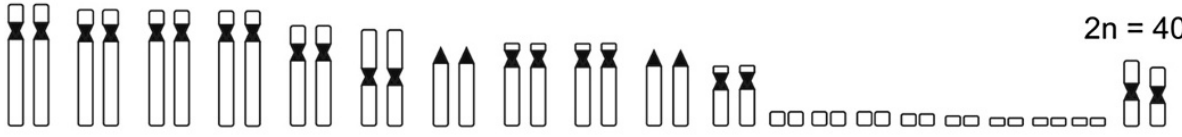

แก

$2 n=30$ (type-C)

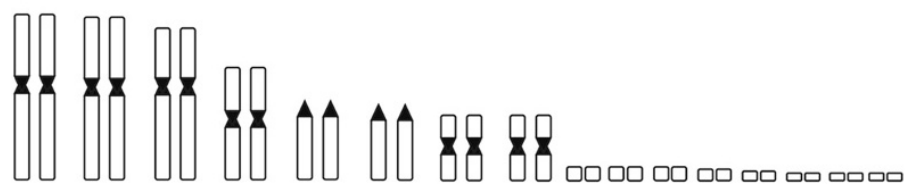

$2 n=32 *$

Figure 2 Ideograms of eight different karyotypes found in Norops males. Dark areas indicate centromeric regions. Asterisks denote that the karyotype with $2 n=32$ is one of the karyotypes found in A. grahami, characterized by a $2 n$ variation. See text for explanation.

microchromosomes (De Smet 1981). The shape of the macrochromosomes, however, differed from both the $2 n=28$ and $2 n=30$ karyotypes. In addition, there were two $\mathrm{X}$ chromosomes and one $\mathrm{Y}$ chromosome $\left(\mathrm{X}_{1} \mathrm{X}_{2} \mathrm{Y}\right)$ in males, all of which were microchromosomes. The female karyotype has not been studied yet, but it is expected to be $2 n=30$ with four $\mathrm{X}$ chromosomes $\left(\mathrm{X}_{1} \mathrm{X}_{1} \mathrm{X}_{2} \mathrm{X}_{2}\right)$.

- $2 n=40$. This karyotype has 12 pairs of macrochromosomes and 8 pairs of microchromosomes. Unfortunately, there were insufficient data to discuss variations of macrochromosomal complements within the $2 n=40$ karyotype because the morphology of the macrochromosomes so far has been studied in only three species: A. dunni, A. taylori (in Lieb 1981), and $A$. unilobatus (this work). The first two species shared a very similar $2 n=40$ karyotype with one large metacentric autosomal pair. However, they have not been studied by molecular methods, and therefore, it is not possible to place them in a phylogenetic context. In addition, Gorman (1973) 
reported a similar, although haploid, karyotype for $A$. tropidogaster. Heteromorphic X and Y (different-sized) chromosomes were described for A. dunni, A taylori, and $A$. unilobatus.

- $2 n=30$ (type-C). Anolis nebulosus showed one more $2 \mathrm{n}=30$ karyotype, but the chromosome arm ratios in the macrochromosomal complement differed with respect to the abovementioned 'ordinary' $2 \mathrm{n}=30$ (type-A) and (type-B). In some specimens, there were at least two pairs of chromosomes in a heterozygous condition of an unknown nature (Castiglia et al. 2010). A similar karyotype may be that found in A. quercorum. These two karyotypes share an apparently similar macrochromosomal constitution, and both have $\mathrm{XY}$ chromosomes that are similar in shape and size (Lieb 1981; Castiglia et al. 2010).

- $2 n=30 \sim 37$. Anolis grahami was characterized by extensive chromosomal polymorphism with chromosome numbers $(2 n)$ ranging $30 \sim 37$ due to multiple fission events within the macrochromosomal complement as well as by eight or nine pairs of microchromosomes (Blake 1986). Only the karyotype with $2 \mathrm{n}=32$ is shown as an ideogram in Figure 2.

- $2 n=42$ (not figured). Anolis nebuloides showed a very distinctive karyotype with the highest diploid number among Norops (Lieb 1981). Except for the four large meta-submetacentric chromosomes, the autosomes had an uncertain morphology. It is worth noting that this karyotype was unique among Norops because chromosomes could not be divided into macro- and microchromosomes. Moreover, the heteromorphic XY chromosomes were of very different sizes. The $\mathrm{X}$ was a large metacentric chromosome, and the $\mathrm{Y}$ was a medium-sized subtelocentric one.

- $2 n=36$ (not figured). Anolis gracilipes had a $2 n=36$ karyotype with four pairs of metacentric and six pairs of acrocentric macrochromosomes and 16 pairs of microchromosomes (reported by Gorman (1973) as 'Gorman unpublished'). This karyotype is very similar (or identical) to that observed in A. gadovii (Lieb 1981). In that species, Lieb (1981) observed heteromorphic sex chromosomes as two metacentrics of different sizes. Molecular data are lacking for these $2 n=36$ species, so it is impossible to properly place them in a phylogenetic context.

- $2 n=38$ (not figured). Anolis liogaster and A. omiltemanus (Lieb 1981) had a karyotype similar to that found in A. taylori $(2 \mathrm{n}=40)$ but with two pairs of large biarmed chromosomes instead of one. No molecular data are available for these species.

\section{Phylogenetic tree}

The phylogenetic tree based on mtDNA genes including all Norops species was fully congruent with previously published phylogenies (Nicholson et al. 2012). The phylogenetic analysis placed A. unilobatus (GenBank accession number KF796613) close to $A$. sericeus and A. isthmicus (with $100 \%$ Bayesian posterior probabilities). The latter two species were not included in the tree (Figure 3) because their karyotypes were not yet available. The affinities found with the phylogenetic analysis concurred with those using morphological data. In fact, A. unilobatus was only recently distinguished from A. sericeus and currently belongs to the same 'species complex' sensu Köhler and Vesely (2010). The resulting topology, once pruned by eliminating species the karyotypes of which were not available, is depicted in Figure 3, 4,5 , and 6 . Some basal nodes were numbered from 1 (the ancestor of all Norops) to 5 to facilitate the description of ancestral states.

\section{Ancestral state reconstruction}

The ASR of anole karyotypes under ML is shown in Figure 3 . It shows ambiguity at node 1 , corresponding to the basal karyotype of all Norops, either $2 \mathrm{n}=28(\mathrm{PL}=0.59)$ or $2 \mathrm{n}=30$ (type-A; $\mathrm{PL}=0.36$ ) (Figure 3 ). The $2 \mathrm{n}=40$ karyotype was more derived and characterized a monophyletic group of 11 species (node 5).

The ASR for macrochromosomes (Figure 4) showed a monophyletic group including all species characterized by a high chromosome number $(2 \mathrm{n}=40$; node 5$)$. The only exceptions were $A$. nebuloides $(2 \mathrm{n}=42)$ and $A$. grahami (polymorphic), in which high diploid numbers occurred independently.

For microchromosomes, the ASR retrieved a tree with uncertainty in the ancestral state of all Norops (node 1; Figure 5). Thus, states 0 (14 microchromosomes; $\mathrm{PL}=$ $0.63)$ and 2 (16 microchromosomes; $\mathrm{PL}=0.35)$ were the most likely to have been retrieved.

In the ASR for the origin of heteromorphic sex chromosomes (Figure 6), the ancestral node for all Norops was coded without heteromorphic sex chromosomes $(\mathrm{PL}=0.99)$. Six independent occurrences of heteromorphic sex chromosomes were observed. It is worth noting that the same types of sex chromosomes, the heteromorphism of macrochromosome 7 and multiple sex chromosomes, resulted from independent origins in groups of three (A. conspersus, $A$. opalinus, and $A$. onca) and two species (A. sagrei and $A$. biporcatus), respectively. Heteromorphic sex chromosomes of different sizes resulted at the origin of the monophyletic group composed of $A$. nebuloides, A. nebulosus, and A. quercorum. It is not clear when these heteromorphic chromosomes arose. Their formation could have occurred at node 4 $(\mathrm{PL}=0.27)$ but was more likely to have occurred in the 


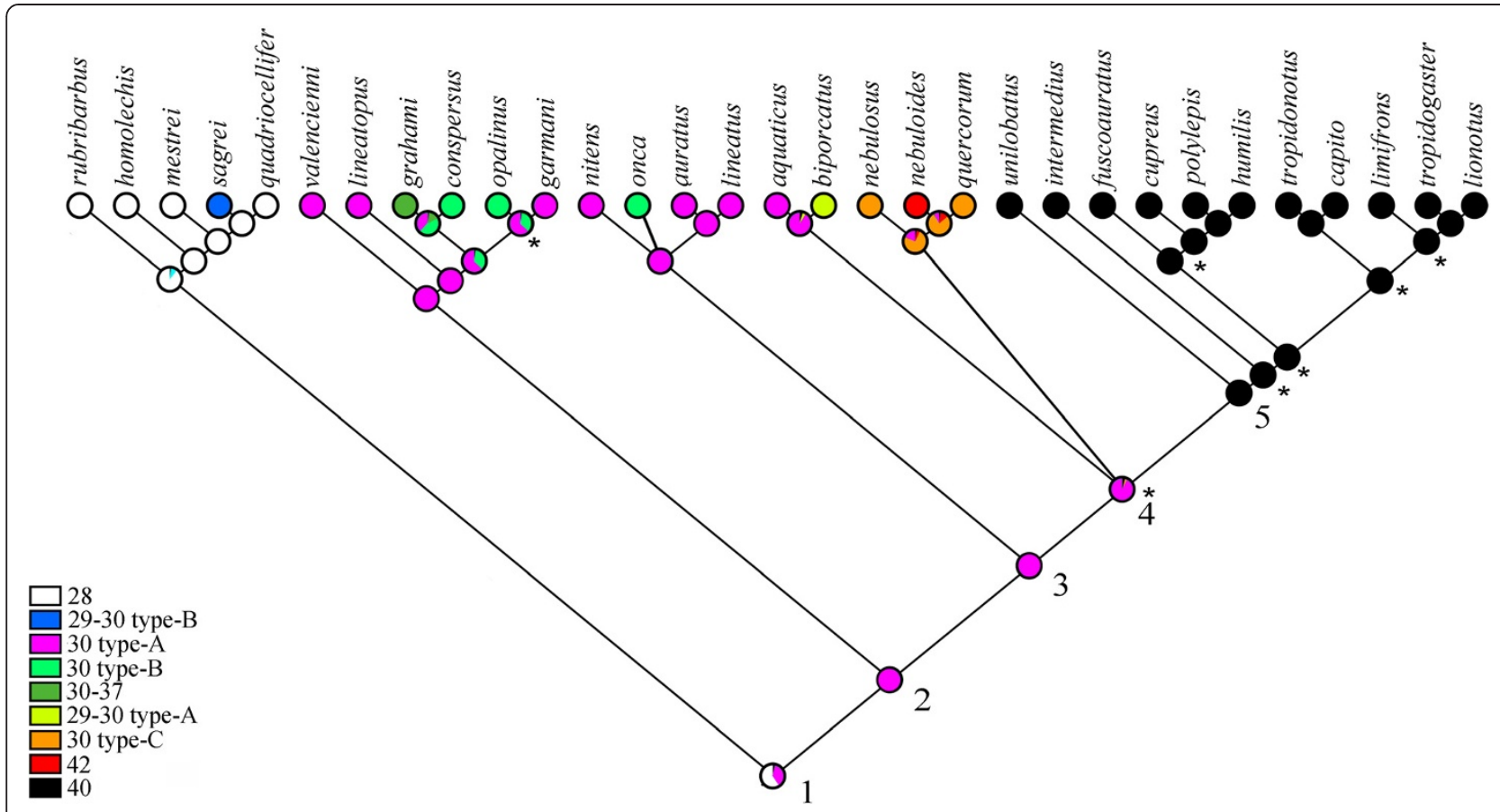

Figure 3 Ancestral state reconstruction of Norops karyotypes. The outgroup is coded as uncertain. Numbers $1 \sim 5$ indicate basal nodes as discussed in the text. All nodes are supported by Bayesian posterior probabilities of $90 \% \sim 100 \%$ with the exception of nodes marked with an asterisk, for which values were $50 \% \sim 89 \%$.

7-9 pairs of macrochromosomes $(28<2 \mathrm{n}<30)$

$10-12$ pairs of macrochromosomes $(2 n=37-42)$

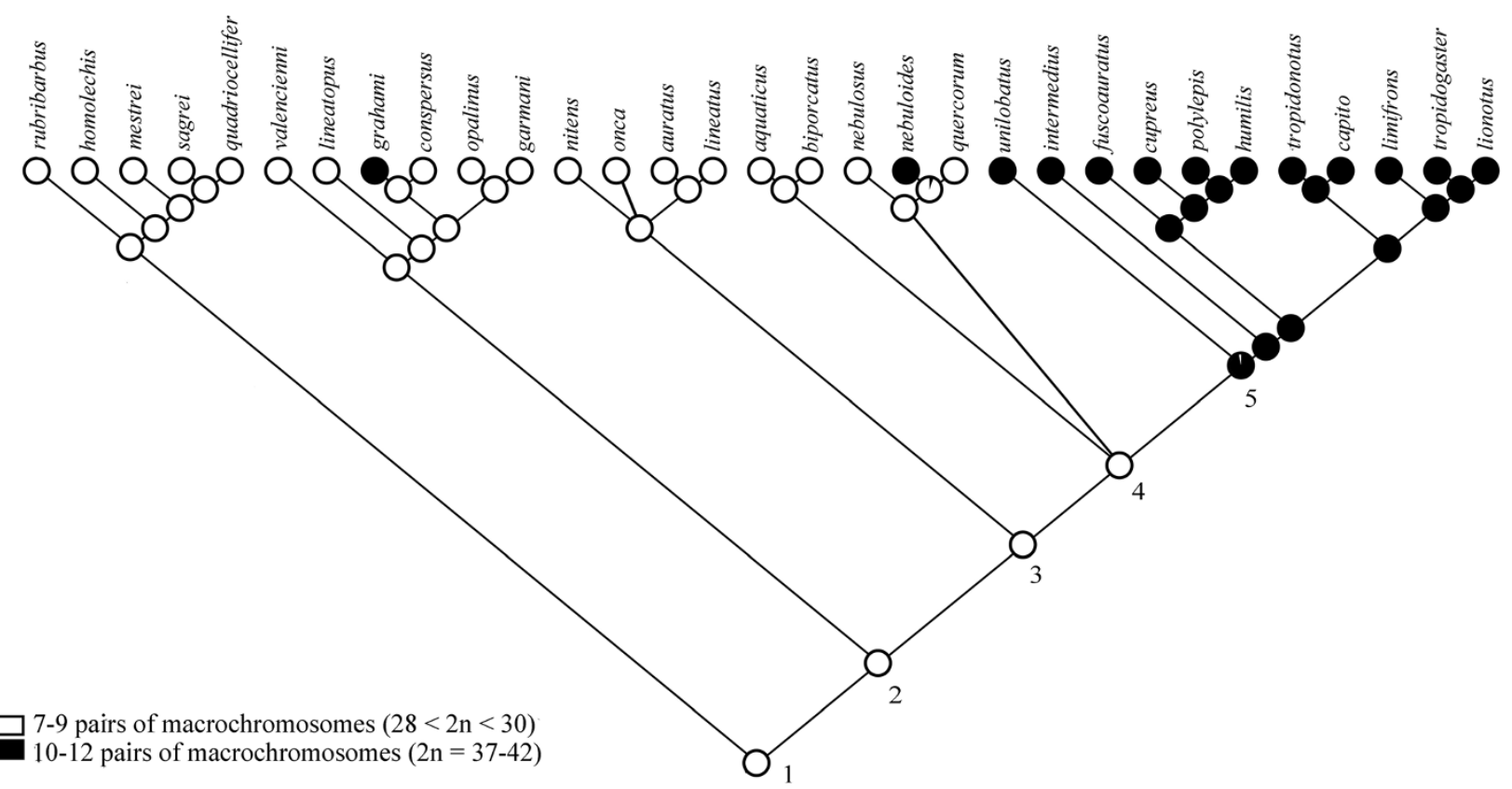

Figure 4 Ancestral state reconstruction of macrochromosomes. The out-group was coded as uncertain. Numbers $1 \sim 5$ indicate basal nodes as discussed in the text. Nodes are supported as described in Figure 3. 


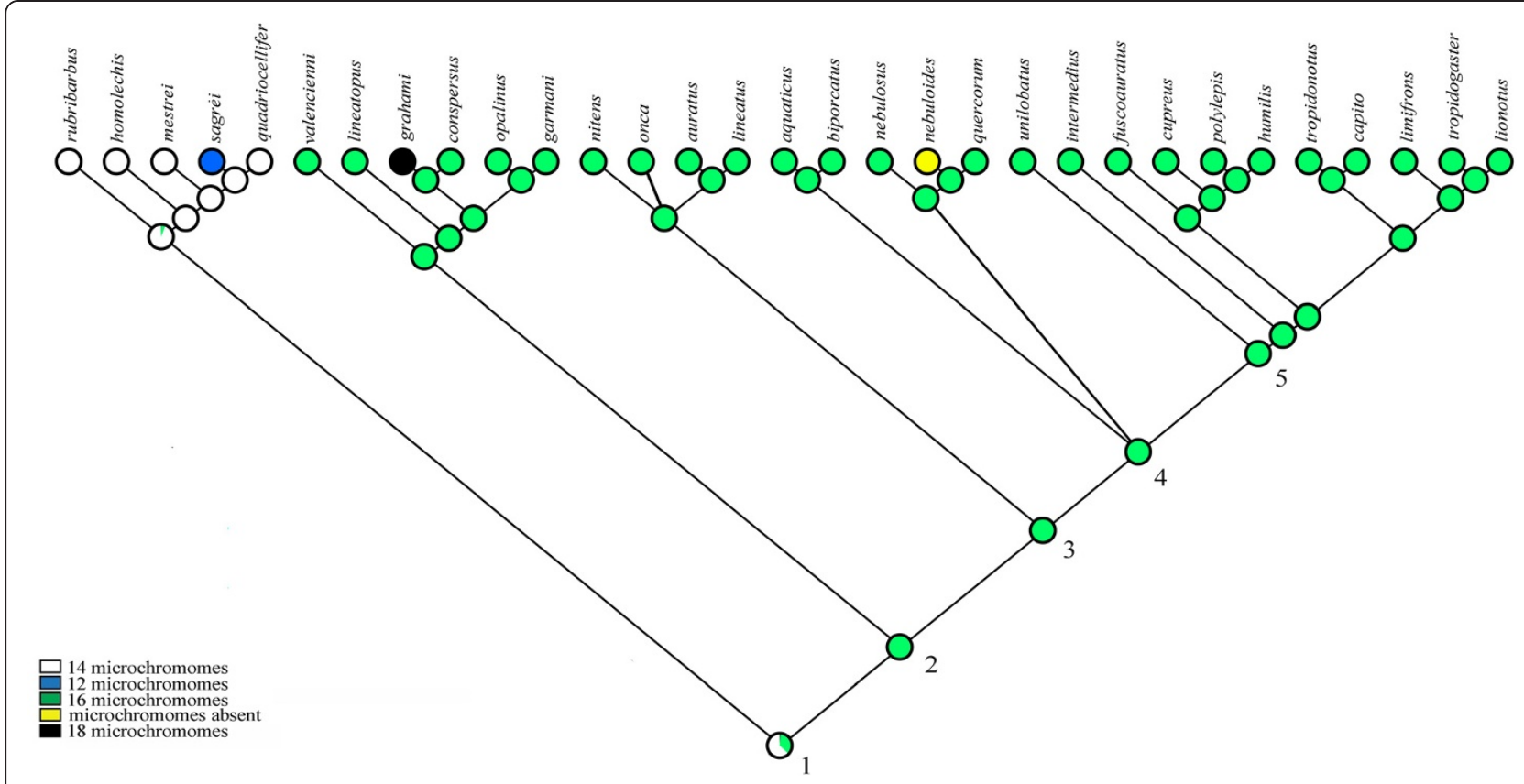

Figure 5 Ancestral state reconstruction of microchromosomes. Numbers $1 \sim 5$ indicate basal nodes as discussed in the text. Nodes are supported as described in Figure 3.

ancestor of the three species $(\mathrm{PL}=0.84)$. Node 5 , basal to $2 \mathrm{n}=40$ species, was uncertain under ML. Under MP, this node was coded equally as state 0 (absence of heteromorphic XY) or 1 (heteromorphic XY) (not shown).

\section{Discussion}

\section{Karyotype evolution in Norops}

We observed an overall good correspondence of some characteristics of karyotype and species relationships. The state change in the number of macrochromosomes and microchromosomes, which altered the diploid number, marked monophyletic groups of species. This correspondence can most likely be 'predictive' of the phylogenetic position of other species for which molecular data are not available. For example, two of the species with $2 \mathrm{n}=40$ studied by Lieb (1981), A. dunni and A. taylori, can possibly be placed within the monophyletic group that was derived from the ancestor at node 5, characterized by $2 \mathrm{n}=40$.

To summarize the results of the ancestral state analysis, the first step during chromosomal evolution of Norops consisted of the emergence or disappearance of a pair of microchromosomes (from node 1 to 2). These events were almost equally probable under the ML reconstruction.

The second main event took place between nodes 4 and 5, where an increase in the number of macrochromosomes from $7 \sim 9$ to 12 pairs took place, accomplished by a change in chromosomal numbers from $2 n=30$ to $2 n=40$. The increase in diploid numbers may be explained by a series of five centromeric fissions that occurred in five pairs of metacentric macrochromosomes in the $2 \mathrm{n}=30$ chromosome complement, which produced chromosomes of the $2 \mathrm{n}=$ 40 karyotype. This is supported by the comparison of the shape of the macrochromosomes in the two karyotypic forms. Indeed, macrochromosomes are metasubmetacentric in karyotypes with a low diploid number $(2 \mathrm{n}=28 \sim 30)$, while in karyotypes with a high diploid number $(2 \mathrm{n}=40 \sim 42)$, macrochromosomes are almost all acro-submetacentric (Table 1). Moreover, some other differences between the $2 \mathrm{n}=28 \sim 30$ and $2 \mathrm{n}=40$ karyotypes are evident. In fact, the presently studied $A$. unilobatus had several submetacentric chromosomes probably obtained by pericentric inversions that followed chromosomal fissions. Interestingly, one species, A. grahami, showed an extensive chromosome number polymorphism $(2 \mathrm{n}=30 \sim 37)$, probably due to multiple Robertsonian fission events in metacentric macrochromosomes (Blake 1986). The high chromosomal number found in A. nebuloides $(2 \mathrm{n}=42)$ also seems to be due to fission events (Figure 4). In fact, the common ancestor of $A$. nebuloides and $A$. quercorum had a $\mathrm{PL}=0.94$ for a low number of macrochromosomes. The present observations concur with the hypothesis that chromosomal fission is a characteristic trait of Norops. Other similar 


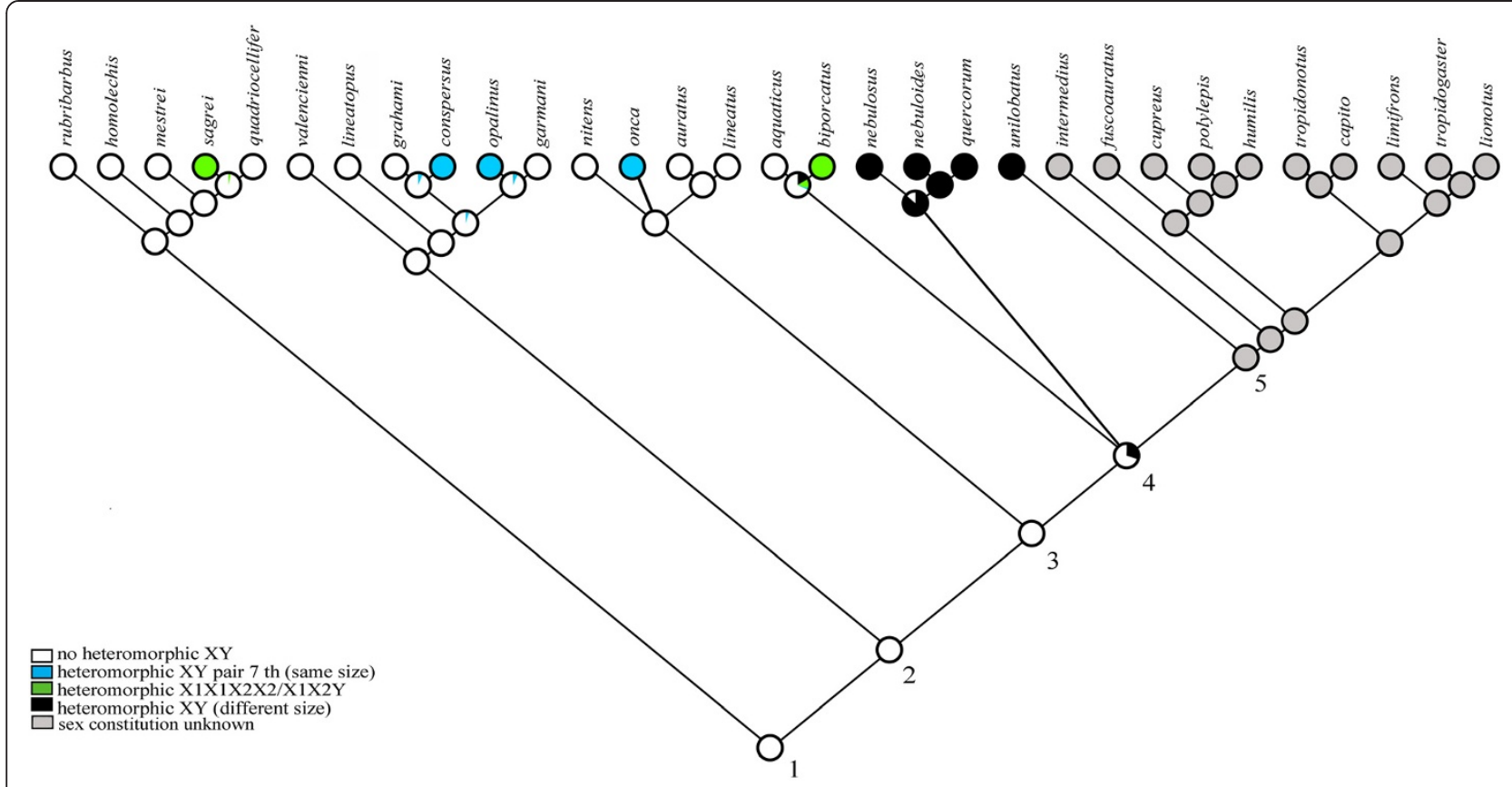

Figure 6 Ancestral state reconstruction of the origin of heteromorphic sex chromosomes. Numbers $1 \sim 5$ indicate basal nodes as discussed in the text. Nodes are supported as described in Figure 3.

studies should be planned to understand whether chromosomal fission is common throughout the genus Anolis. At the moment, it was suggested to occur in at least one more species of anole, Anolis monticola (Webster et al. 1972).

According to Nicholson et al. (2005), mainland species of Norops originated from a West Indian ancestor. In our tree, mainland species all arose from node 3 . Colonization of the mainland almost certainly was carried out by a $2 \mathrm{n}=30$ (type-A) ancestor $(\mathrm{PL}=0.99$ at node 3, in Figure 3). This colonization was followed by an important change in the chromosomal number and a high level of karyotypic diversification. Moreover, karyotypic diversity within the mainland $2 \mathrm{n}=40$ karyotype could possibly have been underestimated because, for many species, macrochromosomes have not yet been studied. One can speculate that chromosomal evolution during adaptive radiation can be driven by adaptation to new environments (the 'canalization model' of Bickham and Baker (1979)). However, no empirical data are currently available to support this issue, and more data on island Norops species are required to properly assess the rate of karyotypic diversification between continental and island anoles.

\section{Sex chromosome evolution}

Sex chromosome heteromorphism was described in nine species of Norops included in this analysis: $A$. biporcatus, A. conspersus, A. nebuloides, A. nebulosus, A. onca, A. opalinus, A. quercorum, A. sagrei, and A. unilobatus. Furthermore, in A. carolinensis, sex microchromosomes (XY) were identified by means of in situ hybridization as two identical microchromosomes (Alföldi et al. 2011). Thus, the absence of evident heteromorphic sex chromosomes does not exclude the possibility of genotypic sex determination.

Our survey showed that there are basically three types of heteromorphic sex chromosomes in the Norops group. Thus, in males of $A$. conspersus, $A$. onca, and $A$. opalinus, the smallest pair of macrochromosomes (number 7) is heteromorphic. In this pair, one chromosome is metacentric, while its homologue is acrocentric and of similar size. Interestingly, A. opalinus and $A$. conspersus are phylogenetically close, as they fall in the same monophyletic group with A. grahami and A. garmani. However, the ASR indicated likely independent origins of sex chromosome heteromorphism in A. opalinus and A. conspersus (Figure 6). Furthermore, according to Pokorná and Kratochvíl (2009), sex-determining mechanisms in Squamata evolved by one-way transition, i.e., from the absence to the emergence of sex chromosomes; therefore, heteromorphic sex chromosomes must have been absent in the common ancestor of the four species of the clade. This implies a motivating hypothesis that sex chromosomes arose independently in A. opalinus and $A$. conspersus. Considering $A$. onca, which is not 
phylogenetically related to the two aforementioned species, the analogous heteromorphism of chromosome pair 7 seems to be another independent event.

The second type of sex chromosomes with $\mathrm{X}_{1} \mathrm{X}_{2} \mathrm{Y}$ males and $\mathrm{X}_{1} \mathrm{X}_{1} \mathrm{X}_{2} \mathrm{X}_{2}$ females was described in A. biporcatus (Gorman and Atkins 1966) and A. sagrei (De Smet 1981). Yet, the sex chromosomes in these two species obviously differ because one of the $\mathrm{X}$ chromosomes and the $\mathrm{Y}$ chromosome are medium-sized in A. biporcatus, while in $A$. sagrei, all sex chromosomes are shaped as microchromosomes (Gorman and Atkins 1966; De Smet 1981). Moreover, A. sagrei and A. biporcatus are unrelated species (Figure 6), and their sex chromosomes might thus have occurred independently. The presence of multiple sex chromosomes is usually due to autosome-sex chromosome translocations (Ashley 2002). The occurrence of such rearrangements has not been studied in Anolis, but our review indicates that the genus may be prone to this kind of rearrangement.

The third sex chromosome constitution was observed in A. nebulosus, A. quercorum, A. nebuloides, and A. unilobatus, in which heteromorphic $\mathrm{X}$ and $\mathrm{Y}$ chromosomes are of different sizes (Lieb 1981; Castiglia et al. 2010). This condition might have easily occurred in the common ancestor of A. nebulosus, A. quercorum, and A. nebuloides (Figure 6). The ancestor at node 5 had an uncertain state because many species have not been studied in detail. Other species of Norops with $2 n=40$, albeit not studied phylogenetically, showed sex chromosomes of different sizes (Lieb 1981). Therefore, we cannot exclude that all descendants from node 5 have this type of heteromorphic sex chromosomes. Additional chromosomal studies of $2 n=40$ species are needed to elucidate this issue.

Considering the 31 species of Norops, the chromosome morphology and molecular DNA data of which are known, a minimum of six independently originated sex chromosome constitutions are possible. It looks like the clade is prone to sex chromosome diversification. Moreover, the origins of five of these heteromorphic sex chromosome variants seem to be recent as they appear at the tip nodes in the ancestral character reconstruction. The potential predisposition to heteromorphism in sex chromosomes revealed in Norops is not unique among reptiles. Actually, many clades at a family level are apparently prone to neosex chromosome formation (Ezaz et al. 2009; Gamble 2010), whereas anoles provide an opportunity to study this phenomenon at a low taxonomic scale, thereby facilitating comparative molecular cytogenetic studies of sex chromosome patterns and elucidation of the possible role of chromosomal differentiation in speciation.

\section{Conclusions}

The ASR analysis of chromosomal characters in Norops allowed us to observe an overall good correspondence of some characteristics of karyotypes (number of macro- and microchromosomes) and species relationships. However, detailed comparative analysis of the morphology of macrochromosomes is still lacking, and here, we were the first to tentatively categorize karyotypes according to macrochromosome morphology and diploid number. Moreover, the clade seems prone to sex chromosome diversification, and the origins of five heteromorphic sex chromosome variants seem to be recent, as they appear at the tip nodes in the ancestral character reconstruction. The observed karyotypic diversification in Norops provides an opportunity to test the chromosomal speciation models and is expected to be useful in studying relationships among anole species and in identifying cryptic taxa.

\section{Competing interests}

The authors declare that they have no competing interests.

\section{Authors' contributions}

$\mathrm{RC}$ conceived the research and performed the analysis. RC, AMRB, and AM collected the specimens. RC, AMRB, and EG performed the laboratory work. $\mathrm{RC}$ and $\mathrm{EG}$ wrote the first version of the manuscript; OFV and AMRB critically read the manuscript and made modifications. All authors read and approved the final manuscript.

\section{Acknowledgements}

We thank Gunther Köehler for his help in identifying Anolis unilobatus and Flavia Annesi for sequencing. Secretaria de Medio Ambiente y Recursos Naturales (SEMARNAT) granted licenses (no. FOV540110) for specimen collection. This work was supported by funds from 'Progetti di Ricerca, di Università' for RC, and AMRB received a postdoctoral fellowship and an 'Atração de Jovens Talentos' researcher fellowship from Conselho Nacional de Ciência e Tecnologia (CNPq).

\section{Author details}

'Dipartimento di Biologia e Biotecnologie 'Charles Darwin', Università di Roma 'La Sapienza', via A. Borelli 50, Rome 00161, Italy. Museo de Zoología, Facultad de Ciencias, Universidad Nacional Autónoma de México, A.P. 70-399, Coyoacán, Mexico, DF 04510, Mexico. Departamento de Zoologia, Universidade de Brasília, IB, Brasilia, DF 70910-900, Brazil. ${ }^{4}$ Current address: Laboratório de Biologia e Parasitologia de Mamíferos Silvestres Reservatórios, IOC-FIOCRUZ, Rio de Janeiro CEP 21045-900, Brazil. ${ }^{5}$ El Colegio de la Frontera Sur - San Cristóbal de las Casas Carr. Panamericana y Av. Periférico Sur s/n 29290, San Cristóbal de las Casas, Chiapas, Mexico.

Received: 1 February 2013 Accepted: 8 October 2013

Published: 13 December 2013

\section{References}

Alföldi J, Di Palma F, Grabherr M, Williams C, Kong L, Mauceli E, Russell P, Lowe CB, Glor RE, Jaffe JD, Ray DA, Boissinot S, Shedlock AM, Botka C, Castoe TA, Colbourne JK, Fujita MK, Moreno RG, Ten Hallers BF, Hausler D, Heger A, Heiman D, Janes DE, Johnson J, De Jong PJ, Koriabine MY, Lara M, Novick PA, Organ CL, Peach SE, et al. (2011) The genome of the green anole lizard and a comparative analysis with birds and mammals. Nature 477:587-591

Ashley T (2002) X-Autosome translocations, meiotic synapsis, chromosome evolution and speciation. Cytogenet Genome Res 96:33-39

Bickham JW, Baker RJ (1979) Canalization model of chromosomal evolution. In: Schwartz JH, Rollins HG (ed) Models and methodologies in evolutionary theory, vol 13. Bulletin of Carnegie Museum of National History, Washington, DC, pp 70-84

Blake JA (1986) Complex chromosomal variation in natural populations of the Jamaican lizard Anolis grahami. Genetica 69:3-17

Brandley MC, Wynn A, De Queiroz K (2006) Karyotype and relationships of Anolis desechensis. J Herpetol 40:136-139

Castiglia R, Annesi F, Bezerra AMR, García A, Flores-Villela O (2010) Cytotaxonomy and DNA taxonomy of lizards (Squamata, Sauria) from a tropical dry forest in 
the Chamela-Cuixmala Biosphere Reserve on the coast of Jalisco, Mexico. Zootaxa 2508:1-29

Cunningham CW (1999) Some limitations of ancestral character-state reconstruction when testing evolutionary hypotheses. Syst Biol 48:665-674

De Smet WHO (1981) Description of the orcein stained karyotypes of 27 lizard species (Lacertilia Reptilia) belonging to the families Iguanidae, Agamidae, Chamaeleontidae and Gekkonidae (Ascalabota). Acta Zool Pathol Antwerp 76:35-72

Etheridge RE (1959) The relationships of the anoles (Reptilia: Sauria: Iguanidae): an interpretation based on skeletal morphology. PhD dissertation. University of Michigan

Ezaz T, Sarre SD, O'Meally D, Graves JAM, Georges A (2009) Sex chromosome evolution in lizards: independent origins and rapid transitions. Cytogenet Genome Res 127:249-260

Gamble T (2010) A review of sex determining mechanisms in geckos (Gekkota: Squamata). Sex Dev 4:88-103

Gorman GC (1965) Interspecific karyotypic variation as a systematic character in the genus Anolis (Sauria: Iguanidae). Nature 208:95-97

Gorman GC (1969) Chromosomes of three species of anoline lizards in the genera Anolis and Tropidodactylus. Mamm Chrom Newsl 10:222-224

Gorman GC (1973) The chromosomes of the Reptilia, a cytotaxonomic interpretation. In: Chiarelli AB, Capanna E (ed) Cytotaxonomy and vertebrate evolution. Academic Press, New York, pp 349-424

Gorman GC, Atkins L (1966) Chromosomal heteromorphism in some male lizards of the genus Anolis. Am Nat 100:579-583

Gorman GC, Atkins L (1968) New karyotypic data for 16 species of Anolis (Sauria: Iguanidae) from Cuba, Jamaica, and the Cayman Islands. Herpetologica 24:13-21

Gorman GC, Atkins L, Holzinger T (1967) New karyotypic data on 15 genera of lizards in the family Iguanidae, with a discussion of taxonomic and cytological implications. Cytogenetics 6:286-299

Köhler G (2000) Reptilien und Amphibien Mittelamerikas, Bd 1: Krokodile, Schildkröten, Echsen. Herpeton Verlag, Offenbach, Germany

Köhler G, Vesely M (2010) A revision of the Anolis sericeus complex with the resurrection of $A$. wellbornae and the description of a new species (Squamata: Polychrotidae). Herpetologica 66:207-228

Leaché AD, Sites JW, Jr (2009) Chromosome evolution and diversification in North American spiny lizards (genus Sceloporus). Cytogenet Genome Res 127:166-181

Lewis PO (2001) A likelihood approach to estimating phylogeny from discrete morphological character data. Syst Biol 50:913-925

Lieb CS (1981) Biochemical and karyological systematics of the Mexican lizards of Anolis gadovi and A. nebulosus species groups (Reptilia: Iguanidae). Ph.D. dissertation. University of California

Losos JB (2009) Lizards in an evolutionary tree: ecology and adaptive radiation of anoles. University of California Press, Berkeley

Losos JB, Jackman TR, Larson A, De Queiroz K, Rodríguez-Schettino L (1998) Historical contingency and determinism in replicated adaptive radiations of island lizards. Science 279:2115-2118

Macey JR, Schulte JA, II, Larson A, Tuniyev BS, Orlov N, Papenfuss TJ (1999) Molecular phylogenetics, tRNA evolution, and historical biogeography in anguid lizards and related taxonomic families. Mol Phylogenet Evol 12:250-272

Maddison WP, Maddison DR (2011) Mesquite: a modular system for evolutionary analysis. Vers. 2.75. http://mesquiteproject.org. Accessed 1 Sept 2013

Nicholson KE, Glor RE, Kolbe JJ, Larson A, Hedges BS, Losos JB (2005) Mainland colonization by island lizards. J Biogeogr 32:1-10

Nicholson KE, Crother Bl, Guyer C, Savage MJ (2012) It is time for a new classification of anoles (Squamata: Dactyloidae). Zootaxa 3477:1-108

Oguiura N, Ferrarezzi H, Batistic RF (2009) Cytogenetics and molecular data in snakes: a phylogenetic approach. Cytogenet Genome Res 127:128-142

Olmo E, Signorino G (2005) Chromorep: a reptile chromosomes database. http://chromorep.univpm.it/. Accessed 23 Sept 2013

Poe S (2004) Phylogeny of anoles. Herpetol Monogr 18:37-89

Poe S (2013) 1986 Redux: new genera of anoles (Squamata: Dactyloidae) are unwarranted. Zootaxa 3626:295-299

Pokorná M, Kratochvil L (2009) Phylogeny of sex-determining mechanisms in squamate reptiles: are sex chromosomes an evolutionary trap? Zool J Linn Soc 156:168-183
Ronquist F, Teslenko M, Van der Mark P, Ayres DL, Darling A, Höhna S, Larget B, Liu L, Suchard MA, Huelsenbeck JP (2012) MrBayes 3.2: efficient Bayesian phylogenetic inference and model choice across a large model space. Syst Biol 61:539-542

Uetz P (2013) The reptile database. http://www.reptile-database.org. Accessed 23 Sept 2013

Webster TP, Hall WP, Williams EE (1972) Fission in the evolution of a lizard karyotype. Science 177:611-613

Williams EE (1983) Ecomorphs, faunas, island size, and diverse end points in island radiations of Anolis. In: Huey RB, Pianka ER, Schoener TW (ed) Lizard ecology: studies of a model organism. Harvard University Press, Cambridge, pp 326-370

\section{doi:10.1186/1810-522X-52-60}

Cite this article as: Castiglia et al: Pattern of chromosomal changes in 'beta' Anolis (Norops group) (Squamata: Polychrotidae) depicted by an ancestral state analysis. Zoological Studies 2013 52:60.

\section{Submit your manuscript to a SpringerOpen ${ }^{\circ}$ journal and benefit from:}

- Convenient online submission

$\checkmark$ Rigorous peer review

- Immediate publication on acceptance

- Open access: articles freely available online

- High visibility within the field

- Retaining the copyright to your article

Submit your next manuscript at $\boldsymbol{~ s p r i n g e r o p e n . c o m ~}$ 